Author: Regina Everitt, Director of Library and Learning Services (LLS)

Institution: University of East London (UEL), University Way, London E16 2RD

\title{
Converging Paths to Common Ground: A Multidisciplinary Approach to Influencing Institution Business
}

Modern academic libraries tend to provide services beyond traditional lending, reference, and enquiry services. Many are converged with other professional or student-focused services such as IT, student services, academic support, or such learning resources as multimedia or print services -- often colocated in space and management structure. At its optimum, this convergence can foster crossinstitution working and enable Library services visibility in institution strategy alongside other business continuity services (e.g., student records, Finance, HR). Conversely, the structure could bury Library services, relegating them to the 'always there, not a problem' box. The visibility of Library services within the converged structure, of course, is dependent on whether the Library leader has influence at the executive table.

Through the prism of the McKinsey 7S framework, this article reflects on the convergence of Library, IT, Multimedia Services including classroom management, and Print Services at SOAS University of London and examines the process of bringing together staff with varying professional identities and grades to work as a cohesive team delivering front-line, customer-focused services. The article also reflects on how taking a multidisciplinary approach to providing institution support enabled the Customer Services and Operations (CSOps) team to influence institution strategy on space development for learning, teaching, and research support.

\section{Background}

SOAS University of London is a world-renowned specialist in the study of Asia, Africa and the Middle East. SOAS Library is one of five National Research Libraries, alongside Cambridge, London School of Economics, University of Manchester and the Bodleian Library. SOAS Library's holdings include 1.3 million items including archives held at Russell Square, significant offsite holdings, and a range of electronic journals, books, and databases. The Library and Archives, which span six floors, received nearly 900,000 visits last year from staff, students, and external researchers and scholars from around the world to access its unique holdings.

SOAS was created by Royal Charter in 1916 and the Library was also created in that year with the Director of SOAS, Sir E. Denison Ross appointed as Librarian. Sir Denison Ross was a linguist and specialist in languages of the Far East. He developed the Library with books and journals mostly on the study of Asian languages and cultures consolidated from other University of London libraries (Lodge 1968).

Though the SOAS of the past trained civil servants in languages and cultures to enable them to manage British colonies, the modern SOAS challenges the status quo and seeks to lead the fight for social justice. Freedom of speech and tolerance, core values at SOAS, are at the root of the culture where perceived knowledge, expertise, and authority are challenged. Leading and managing in this 
Author: Regina Everitt, Director of Library and Learning Services (LLS)

Institution: University of East London (UEL), University Way, London E16 2RD

cultural context is challenging as initiatives or changes could be actively resisted if deemed unworkable or unpopular. An attempt in 2005 to implement a Library restructure resulted in a highprofile case that required third-party mediation to resolve (Baty 2005).

In 2009, the Library and Archives were converged with IT and the joint directorate became Library and Information Services (LIS). LIS comprised Library, Archives, IT (including help desk, corporate systems, infrastructure, networks, telephony), IT training, Multimedia services (then called IT/AV), and Print Services including the Print Room. The LIS senior management team comprised the Director supported by five Assistant Directors: Information Services, Operations (me), Bibliographic Services, Teaching and Research Support, and Archives and Special Collections. The convergence preceded my time at SOAS, but the rationale was about efficiencies and economies of scale of combined information services under a single director, which also resulted in one less direct report for the Registrar at the time.

I joined SOAS as Assistant Director (Operations) in 2013 amid warnings about the challenging management environment there. The Operations division had yet to be formed, so comprised some 61 posts with a supervisory level staff member who led the team that kept the Library doors open and a manager who looked after the technical teams. Effective line management and staff development and support were virtually impossible due to the sizes of the teams. At Assistant Director level, I should have been making strategic decisions about service development and relevance to institution direction; however due to a lack of structure, I was continuously drawn into operational details such as dealing with the rota, responding to noise complaints in the Library or clearing up spills and reporting faults to Estates.

Meanwhile, the SOAS 2020 Vision and Strategy cited improvement to Library access and resources as a priority (SOAS 2012). As the operations teams were the first point of contact for all LIS services, I had to get the teams working together to meet this strategic objective.

\section{The McKinsey 7S Framework and Other Methods}

As I considered how to re-shape the Operations division, I immediately began to plan hierarchies and structures to build in leadership and support for the various teams. As I was expected to deliver on some projects fairly quickly after my arrival, I had little time to really think. Now reflecting on the implementation of the change programme and the resulting service delivery, I looked to the literature for frameworks for evaluation.

In the past, I used the McKinsey 7S framework with peers as we developed our strategy for professional services in alignment with the wider institution strategy. Developed by McKinsey \& Company, a global management consultancy, the framework is used in organizational development to think beyond structures when planning and implementing strategy and consider all the elements or relationships that enable the organization to operate (Waterman et al 1980). The framework uses seven elements to analyze organization design: strategy, structure, systems, shared values, style, staff, and skills. The hard elements are those items that are more easily identifiable or definable: strategy, structure and systems. The remaining four elements are 'soft' as they are less easily 
Author: Regina Everitt, Director of Library and Learning Services (LLS)

Institution: University of East London (UEL), University Way, London E16 2RD

definable (Mindtools n.d.). I was drawn to the holistic approach of the framework, seeking to balance the range of elements that make the institution function. Cameron and Green refer to this balancing as homeostasis noting that if the relationships are not aligned, they will not function (Cameron \& Green 2012). In the SOAS context, shared values and style (or culture) are particularly resonant as overlooking these elements could have adverse impacts on any initiative.

The Galbraith star model takes a similar approach to looking at relationships between people, strategy, structure, rewards, and processes (Galbraith 2012). As with the McKinsey model, the strategy, the direction of the institution; the structure, the hierarchy; and the processes or systems can be viewed as the hard elements whilst the people and rewards can be viewed as the soft or less definable elements. Again, the organization design would seek to balance these elements.

Similarly, Leavitt's diamond model and Weisbord's six-box model both look at the interdependence of these hard and soft elements (Kral \& Kralova 2016). Structure, people or relationships and processes all feature in some form. Unlike the McKinsey model, shared values and style (culture) are not foregrounded as specific elements. Tichy in analyzing the interrelated elements of organization structure discussed bringing together subcultures to create the larger institution culture (Tichy 1982). In the SOAS context, the institution is training future activists and leaders of social justice, so the dominant culture is that of challenging authority and the status quo.

For this article, I am using the McKinsey 7S framework post-implementation to reflect on my approach to developing the teams to deliver services that are integral to the institution's business. In the figure below, I have populated the elements of the framework with my thinking as I considered the strategic direction of the Operations division and embarked on the change programme.

\section{7-S Framework}

\begin{tabular}{|l|l|}
\hline Strategy & $\begin{array}{l}\text { Centalized, front-line teams to deliver seamless, customer-focused } \\
\text { services to support the learning, teaching and research needs of the } \\
\text { institution. }\end{array}$ \\
\hline Structure & $\begin{array}{l}\text { Teams with multidisciplinary portfolios operating from shared service } \\
\text { points (where feasible) and led by managers/team leaders/supervisors. }\end{array}$ \\
\hline Systems & $\begin{array}{l}\text { Consistent processes, procedures, and tools for reliable and professional } \\
\text { service delivery. }\end{array}$ \\
\hline Shared values & Enablers rather than gatekeepers; customer-focused. \\
\hline Style & Coaching; democratic, where practical. \\
\hline Staff & Adaptable while maintaining professional identities. \\
\hline Skills & $\begin{array}{l}\text { Cross-trained to enable seamless, multidisciplinary approach to service } \\
\text { delivery. }\end{array}$ \\
\hline
\end{tabular}


Author: Regina Everitt, Director of Library and Learning Services (LLS)

Institution: University of East London (UEL), University Way, London E16 2RD

\section{Strategy and Structure}

To say that the LIS teams were weary of change is an understatement. They had undergone the convergence of Library, IT and AV in 2009/10. Then a minor restructure of IT in 2010/11. The team that I took on in 2013 comprised the Reader Services team, $1^{\text {st }}$ and $2^{\text {nd }}$ line IT, IT/AV team, which also supported conferencing and the fleet of printer/scanner/copiers, IT trainer, and the Print Room. The Reader Services team also had responsibility for id card production for the whole institution and was relied on to produce these during enrolment periods. These disparate teams appeared to have no unified purpose so continued to work as they did before convergence of the services. However, they shared a key function: they were all customer-facing. And as the first point of contact for all users of the services, their approach to service delivery would impact access to resources. Again, the 2020 strategic objective was to improve access to Library services.

A major refurbishment project in 2011 led to an increase in study spaces and the modernization of a large part of the Library. So, from the space perspective, the 2020 objective was being implemented. Yet, qualitative feedback from users indicated that improvements were needed to how services were delivered. Front-line staff members took on a 'gate-keeping' approach, interrogating users to determine eligibility to access resources. I sought to shift to an 'enabling' approach where staff assisted users with accessing resources within SOAS Library or partner institutions. This would mean a culture shift and rethinking the team structures and duties. Also, policies such as drinks in the Library were relaxed, thus relieving staff members of some 'policing'.

I began consulting on structures that would build a management team to support me in embedding a customer-focused ethos whilst assisting with daily operations, staff development, and performance management. Although committed to supporting all staff members, it was impossible for me to provide individual support to such a large and diverse team. The managers also had to take a multidisciplinary approach to working. So, although their specialism may have been in Libraries, for example, they needed to be cross-trained and willing to deal with issues arising from any area of the business and cover for one another during absences. And, ultimately, staff would be asked to do the same.

\section{Staff and Skills}

I changed some of the legacy job titles and descriptions to support the direction of travel and to align with similar roles in the sector. Staff members could then network with external peers in similar roles to enable skills and service development. I underestimated how 'dis-identification' with one professional identity and 're-identification' with another would impact some staff members (Chreim 2002).

For the most part, the shifts in the titles of Microcomputing Support Analyst to Service Desk Support Assistant and Library Services Support Officer to Library Assistant were straightforward. The term microcomputing is rarely used so disconnected the team from any peer support network. I brought in an external facilitator to train and certify the Service Desk team in IT industry-standard service management and Information Technology Infrastructure Library (ITIL) principles. This enabled the team to share best practice with internal IT teams and linked them with a support network (and career 
Author: Regina Everitt, Director of Library and Learning Services (LLS)

Institution: University of East London (UEL), University Way, London E16 2RD

options) externally. The participation of an IT colleague from a local institution also reinforced the industry application of the principles; the skills learned were applicable beyond SOAS.

Library Services Support Officer is a nebulous title with little meaning within the sector. The responsibilities of the role had expanded well beyond managing the cloakroom (which had been absorbed into the Library space many years before) to general enquiries and stock control. Not only does Library Assistant link the team to a wide external network, the title also links more clearly to the progression route to Senior Library Assistant, Librarian and beyond.

The concerns raised about the shift from Reader Services to Customer Services is well-rehearsed in the HE sector. To some 'customer' denotes a commercial transaction arguing that students are not 'buying' their degrees. The fact that students (and their parents) as consumers 'shop' around for the best 'value' for money evidences the marketization of HE. The Office for Students (OfS) also notes on its website that students should 'receive a good deal for their investment' (OfS 2017). Redding compares the US fee-paying model to the UK tax-paying model to highlight the difficultly in the UK of viewing students as consumers but concludes that whatever students are called, they want their needs served (Redding 2005). 'The Customer Services Excellence accreditation, which the Customer Services team earned in 2017, further embeds the use of the term 'customer'.

The shift from AV, IT/AV or Media technician to Multimedia Services Analyst raised concerns from technical staff. My rationale for the change was to shift the perception that the team simply pushed trolleys of projection equipment around the campus. In reality, the team helped to define, install and maintain the equipment in the classrooms, film and record events and tutorials then edited the works for upload on the institution YouTube channel or VLE, provided inductions on use of video, audio, photography, and other equipment, and provided classroom support for editing classes. With technologies coming together - video and sound running on PCs or printers enabling application conversions - the skill set of the 'technician' is ever-expanding. So, I sought a title that would encompass the range of services that they delivered.

The team members felt otherwise. They identified with 'AV', with some individuals specializing in sound, video, lighting, etc. Though, in my view, I was not asking them to 'dis-identify' with the AV profession, the requirement for them to 're-identify' with 'multimedia' was an uncomfortable fit for some team members. Chreim's reference to 'dis-identification' was in the context of shedding one identity to assume the required identity of the new structure (re-identification). This was not my intention for any of the changed roles. In fact, I sought what I will call 'cross-identification', where staff members could identify with a range of roles beyond their specialisms to deliver a range of services. In the end, it was the Technicians' own approach to team working that led to cross-training. They were accustomed to working in pairs or groups to support events and understood the need to cover one another for absences. However, when describing themselves in meetings, they tended to say that they were AV or IT/AV. In a cursory check of the use of Multimedia vs. AV or IT/AV in jobs listings, the former was never used, admittedly. I still believe that IT/AV under sells the creativity and diversity of their roles, but acknowledge their strong identification with the title.

With a full management team recruited by the end of 2014 and fully staffed by early 2015 , we embarked on rolling out cross-training to staff members so that they could provide a breadth of 
Author: Regina Everitt, Director of Library and Learning Services (LLS)

Institution: University of East London (UEL), University Way, London E16 2RD

support to users before referring them to specialist teams. This cross training would be particularly useful during busy periods, evenings and weekends when specialist staff members were not immediately available.

\section{Systems and Shared Values}

Just prior to my arrival at SOAS Library, a very expensive, but very traditional front desk was installed as part of refurbishment. The desk comprised multiple service points: $1 \mathrm{x}$ membership, $1 \mathrm{x}$ turnstile operations/general enquiries, $3 \mathrm{x}$ issue, $1 \mathrm{x}$ reference enquiries, $2 \mathrm{x}$ IT enquiries. The self-service machines were located in front of the long front desk. Needless to say, users deferred to the staff member waiting at the service point rather than attempted a transaction, no matter how routine, on a self-service machine. Users appeared to do a cost/benefit analysis to queuing, assessing the length of time they had to wait against the success or failure of attempting the transaction on their own.

(Conte 2016). Staff members focused only on their assigned desks; a staff member working on the issue desk would not deal with queries about access blocks or general access, for example.

Reference enquiries were dealt with largely by Librarians. IT queries were only dealt with by IT staff members.

In the same way that I cross-trained managers in understanding the basics of other services within LIS, I sought to do the same with staff members so that they could respond to a range of queries at the service point. I also sought to implement a roving model that would allow staff members to meet users at the point of need rather than passively wait for them to come to the service point. The desk design hindered this model as staff members could not easily move from behind it. The positioning of the turnstiles, gate, and entrance were all based on the positioning of the desk. In short, to change the desk would mean a complete refurbishment of the front of Library. Beyond the physical structures, staff members and ultimately users, came to believe that the desk was 'broken' if all eight positions were not filled, despite the fact that the self-service units were effectively used during evenings, weekends, and holidays.

At a previous Library, I arranged peer-led cross-training to enable staff members to answer questions beyond their specialisms. For example, IT staff members were trained on basic Library queries re: how to use the online catalogue. Introduction of this model was met with resistance at SOAS from some vocal staff members who claimed that I was encouraging staff members to do others' jobs. Meanwhile in individual meetings with managers, staff members expressed interest in learning other skills or confessed having knowledge in areas outside their specialism that could benefit the service. However, they were reluctant to openly support the new way of working in light of the vocal pockets of resistance within the team and the culture of collective action within the institution.

The early adopters of the multidisciplinary way of working was the weekend team as they collectively sought to deliver as much of the core hour services as possible without the benefit of access to specialist support (e.g., IT, regional librarians). Those staff members who worked weekends carried their multidisciplinary approach to week days when they were on shift. They simply 
Author: Regina Everitt, Director of Library and Learning Services (LLS)

Institution: University of East London (UEL), University Way, London E16 2RD

led by example by dealing with a range of queries no matter where they were positioned at service points. Over time more staff members became more comfortable and confident in dealing with a range of queries. The move to an open source Library system which required development and testing, encouraged IT staff members to learn more about how Library records are managed - so more cross-working. Finally, departure of some staff members and active recruiting of staff members who would work more flexibly refreshed thinking about the boundaries of front-line support roles.

\section{Style (Culture)}

Like many Library services, SOAS Library has a number of long-serving staff members, some of whom also studied at the institution. So, these staff members have a long-term psychological contract with the institution and many seek to preserve its culture of collective action. I took a coaching and democratic approach to leadership as I wanted to use the institution knowledge and skills of the teams to shape the service. By aligning the team roles with those of the sector, I could more easily link them with training, conferences, and peer support networks to keep abreast of sector best practice. I then got them to consider how some of the services, processes and procedures could be implemented within the SOAS context. I also took opportunities to allow staff members to lead on activities such as developing the staff code of conduct, developing and maintaining the service desk manual, and developing a structured approach to resource planning for multimedia equipment. I enabled secondment opportunities within and outside the division so that staff members could have experience working with other teams. I also ensured that staff members were part of institution committees and project teams to increase their and the directorate's exposure. Staff training in ITIL, Agile, and workplace mediation enabled team members to speak in the language of a range of specialisms from IT to project management to HR and more. The teams were trained and ready to work in a multidisciplinary way. 
Author: Regina Everitt, Director of Library and Learning Services (LLS)

Institution: University of East London (UEL), University Way, London E16 2RD

\section{Influencing Institution Business}

On reflection, the transformation of the CSOps team could only have been achieved through the balancing of the 7Ss. The teams have gained confidence in acting as enablers of a range of services. They are integral to major events such as open days, enrolment, and graduation. As the Multimedia Services team assisted with classroom design, we successfully lobbied the Pro Director for Learning and Teaching to include classroom design in strategic planning so that spaces would be designed and equipment installed that met the current and emerging teaching, learning and research needs of the institution. In the past, classroom refurbishments were based on Estates condition surveys and did not consider the activities to take place within the spaces. I have also recommended that space use be included in training sessions for new lecturers alongside use of technologies such as lecture capture.

As staff members were trained to work across disciplines, they contributed to major projects such as access control for the campuses, upgrades to the intranet, and changes to identity management. A trained process reviewer, I led a review of degree transfers for Registry. As the first service at SOAS to achieve CSE, the CSOps team planned to exchange knowledge with the Student Hub team on how to achieve the accreditation. The team also trained Student Hub staff members on id card production, a process that the CSOps team streamlined. Staff members signed off on programme proposals, ensuring that resources such as books, e-resources, IT and multimedia equipment and software were available to support courses and research. Senior staff members were part of such institution committees and working groups as Academic Board, TEF Planning, Student Experience, and Research and Enterprise, to name a few. Visibility via all of these activities enabled Library services to be integral to institution business.

\section{Deconvergence ... reclaiming professional identities?}

Nearly eight years after convergence of LIS, the services have de-converged. Having worked hard with staff members to make the CSOps multidisciplinary team work, I have come full cycle to separate the services. Cross-institution staff consultation suggested that there was an appetite for the services to part ways and showcase their individual strengths under separate directors who could focus on developing the individual services. So, staff members reclaimed professional identities in some respect. However, through participation in institution-wide projects, staff members now have a better understanding of how the institution works and how their roles contribute to the academic mission. There are clearer progression routes to other areas of the department and the institution such as IT, student services or academic services for those staff members who have training in ITIL, service desk management, learning technologies, or project management. They also have links to external peer groups in similar professions. Library Director portfolios have expanded with many leading student or academic services or IT. They are also asked to lead cross-institution initiatives so need to be confident in operating outside the Library envelope.

The incoming SOAS Library Director will have further need to review the 7Ss to enable the teams to 
Author: Regina Everitt, Director of Library and Learning Services (LLS)

Institution: University of East London (UEL), University Way, London E16 2RD

deliver relevant services to meet the current and emerging learning, teaching, and research needs of SOAS as well as maintain the National Research Library status. So, the need for staff members to continue to cross-train and work in a multidisciplinary way will not change. In fact, as budgets constrict, institutions will need a versatile workforce to continue to deliver excellence with existing rather than increased resources. Mortensen and Gardner talked about 'overcommitted' professionals working on multiple teams and the duty of care of organizations to mitigate against burnout (Mortensen \& Gardner 2017). However, they still highlight the benefit of knowledge sharing and cross team working to realize resource efficiencies.

-End- 
Author: Regina Everitt, Director of Library and Learning Services (LLS)

Institution: University of East London (UEL), University Way, London E16 2RD

\section{Bibliography}

Baty, Phil, 2005, 'SOAS to Review Library Layoffs,' Times Higher Education Supplement, 1716: 6. (accessed 27 December 2017), <https://www.timeshighereducation.com/news/soas-to-review-librarylayoffs/199489.article>

Cameron, Esther \& Green, Mike, 2012, Making Sense of Change Management: A Complete Guide to the Models, tools and Techniques of Organizational Change, $3^{\text {rd }}$ edition, Kogan Page Limited, London.

Chreim, Samia, 2002, 'Influencing organizational identification during major change: a communication-based perspective,' Human Relations, 55 (9): 1117-1137.

Conte, Anna, Scarsini, Marco \& Surucu, Oktay, 2016, 'The impact of time limitation; Insights from a queueing experiment,' Judgement and Decision Making, 11(3), 260-274.

Galbraith, Jay, R., 2012, 'The Evolution of Enterprise Organization Design,' Journal of Organization Design, 1(2), 1-13.

Kral, Pavel \& Kralova, Vera, 2016, 'Approaches to changing organizational structure: The effect of drivers of communication,' Journal of Business Research., 69, 5169-5174.

Lodge, A., 1968, "The History of the Library of the School of Oriental and African Studies." In University and Research Library Studies, edited by Saunders, W.L. 1968, 84-110. London: Pergamon Press Ltd.

Mindtools, The McKinsey 7S Framework: Ensuring That All Parts of Your Organization Work in Harmony, accessed 19 March 2018 from https://www.mindtools.com/pages/article/newSTR 91.htm.

Mortenson, Mark \& Gardner, Heidi K., 'The Overcommitted Organization: Why It's Hard to Share People Across Multiple Teams And What To Do About It,' Harvard Business Review, SeptemberOctober 2017, 58-65.

Office of Students, New universities regulator comes into force: The Office for Students comes into force to hold universities to account and promote students' interests, accessed 14 March 2018 from https://www.gov.uk/government/news/new-universities-regulator-comes-into-force.

Redding, Peter, 2005, 'The evolving interpretations of customers in higher education: empowering the elusive,' International Journal of Consumer Studies, 29(5), 409-417.

SOAS University of London, 2012, 2020 Vision and Strategy for the 2016 Centennial and Beyond, brochure, London.

Tichy, Noel, 1982, 'Managing Change Strategically: The Technical, Political, and Cultural Keys,' Organizational Dynamics, 11(2), 59-80.

Waterman Jr., Robert H., Peters, Thomas, and Phillips, Julien, 1980, "Structure is not Organization". Business Horizons 23 (3): 14-26. 